\title{
Father's Education: An Independent Marker of Risk for Preterm Birth
}

\author{
Philip M. Blumenshine $\cdot$ Susan A. Egerter • \\ Moreen L. Libet $\cdot$ Paula A. Braveman
}

Published online: 16 January 2010

(c) The Author(s) 2010. This article is published with open access at Springerlink.com

\begin{abstract}
To explore the association between paternal education and preterm birth, taking into account maternal social and economic factors. We analyzed data from a population-based cross-sectional postpartum survey, linked with birth certificates, of women who gave birth in California from 1999 through $2005(n=21,712)$. Women whose infants' fathers had not completed college had significantly higher odds of preterm birth than women whose infants' fathers were college graduates, even after adjusting for maternal education and family income [OR $(95 \%$ CI) $=1.26(1.01-1.58)]$. The effect of paternal education was greater among unmarried women than among married women. Paternal education may represent an important
\end{abstract}

When this research was conducted, Philip M. Blumenshine was a Doris Duke Clinical Research Fellow at the University of California, San Francisco.

P. M. Blumenshine

Weill Medical College, Cornell University, New York, NY, USA

\section{S. A. Egerter}

Department of Family and Community Medicine, University of California, San Francisco, San Francisco, CA, USA

\section{L. Libet}

Maternal, Child and Adolescent Health Program, California Department of Public Health, Sacramento, CA, USA

\section{P. A. Braveman}

Department of Family and Community Medicine, University of California, San Francisco, San Francisco, CA, USA

\section{S. A. Egerter $(\square)$}

Center on Social Disparities in Health, University of California,

San Francisco, 3333 California St., Ste. 365, UCSF Box 0943,

San Francisco, CA 94118, USA

e-mail: egerters@fcm.ucsf.edu indicator of risk for preterm birth, reflecting social and/or economic factors not measured by maternal education or family income. Researchers and policy makers committed to understanding and reducing socioeconomic disparities in birth outcomes should consider paternal as well as maternal socioeconomic factors in their analyses and policy decisions.

Keywords Epidemiology · Preterm birth - Risk factor · Socioeconomic factors

\section{Introduction}

Preterm birth accounts for $\sim 75 \%$ of perinatal morbidity and mortality in the industrialized world [1] and was associated with an economic cost of over $\$ 26$ billion in the United States during 2005 [2]. This substantial public health burden is disproportionately borne by women and infants in low-income families and in minority racial or ethnic groups [3], and has implications for health status not only during childhood but later in life as well [4]. Despite the clear public health importance of preterm birth, current knowledge of its etiology and how to intervene remain limited [2].

Research on social disparities in preterm birth has focused primarily on the role of maternal characteristics. In the United States, preterm birth has been associated with mother's income, education, and occupation among both black and white women, as well as with maternal race or ethnic group [5]. Less is known about the role of paternal factors, however. Previous studies have identified a relationship between low levels of paternal educational attainment and low birthweight, but were limited by lack of information on potential confounders and substantial missing data for paternal education [5-10]. Paternal 
educational attainment-or factors closely associated with it-could be one of the missing pieces of the puzzle of disparities in preterm birth. Paternal social factors could influence preterm birth in important ways, after accounting for maternal factors. For example, higher paternal educational attainment could reflect higher social status that enables a woman's partner to provide her with greater material and/or psychosocial resources, including support for healthy maternal behaviors and creation of a less stressful environment. Understanding the role of paternal social factors could be important for shaping the nature of interventions to address preterm birth disparities, potentially redirecting the focus of large programs such as Healthy Start.

Despite the potential importance of paternal socioeconomic factors, we have not identified published articles focused on the relationship between paternal educational attainment and preterm birth. This study examines the association between paternal education and preterm birth using data from California's population-based Maternal and Infant Health Assessment (MIHA) survey, a data source that permits consideration of family income, maternal educational attainment, age, parity, and marital status.

\section{Methods}

\section{Study Design/Research Subjects}

The Maternal and Infant Health Assessment (MIHA) is a statewide population-based survey of maternal/infant health and related sociodemographic, behavioral, and psychosocial factors and has been conducted annually since 1999. A woman is eligible for MIHA if she is a California resident who has a singleton, twin or triplet live birth between February and May, is age 15 years or older at the time of delivery, and speaks English or Spanish. Eligible mothers are grouped into strata defined by race, educational attainment, and region of the state; African American women are over-sampled to allow for a sufficient sample size to validly measure within-group maternal and child health risks and outcomes. Women who do not return the initial mailed questionnaire are sent a reminder postcard and a second questionnaire, after which attempts are made to survey them by phone. Response rates have been $70 \%$ or higher annually, yielding a final sample each year of $\sim 3,500$ women. Characteristics of sampled women, weighted to reflect the sampling frame, correspond closely with those of all women with live births statewide, based on birth certificate data (available on request). Completed surveys are linked with birth certificate data on type of delivery, gestational age, maternal age and parity, and maternal and paternal education. Detailed information about MIHA has been published elsewhere [11-15] and is available at http://www.cdph.ca.gov/data/surveys/Pages/ MaternalandInfantHealthAssessment(MIHA)survey.aspx.

The current study analyzed pooled MIHA data on women surveyed from 1999 to 2005.

\section{Measurements}

Preterm birth was defined as delivery at less than 37 weeks of gestational age, following the World Health Organization definition [16]; births at or after 37 weeks were considered to be full-term. Data on gestational age were obtained from birth certificates, and MIHA replaces improbable gestational ages with imputed values based on birth weight and sex.

We examined three socioeconomic factors. Family income was based on self-reported before-tax annual income categorized in percentage increments of the federal poverty level (FPL), which has been defined as the amount of income providing a bare minimum of food, clothing, transportation, shelter and other necessities. FPL is reported annually and varies by family size; in 2005 , the FPL was $\$ 19,350$ for a family of four [17]. Women with family incomes greater than $400 \%$ FPL were the reference category. Maternal and paternal educational attainment (hereafter, "education"), obtained from birth certificates and recorded as number of years of completed schooling, were grouped into four categories corresponding to earned credentials: women or men with less than a high school education (fewer than 12 years of schooling), those who had completed high school (12 years), those with some college (13-15 years), and the reference group of those who had completed college $(16+$ years of schooling). Racial or ethnic group, an important social construct often associated with socioeconomic factors, was recorded in MIHA and classified into six mutually exclusive categories: African American, Asian/Pacific Islander, European/Middle Eastern (the reference group), foreign-born Latina, U.S.-born Latina, American Indian/ Alaskan Native, and "other" or "unknown" ethnicity; respondents who reported being in multiple racial or ethnic groups were asked to choose their primary group. American Indians/Alaskan Natives $(n=131)$, and women with "other" or "unknown" ethnicity $(n=451)$ were excluded from all analyses because of small numbers. Asians and Asian-Americans $(n=2,264)$ were also excluded because of concerns about whether MIHA, which is administered only in English and Spanish, provides a representative sample of childbearing women in this group.

We also examined the following variables because of their likely associations with both paternal education and preterm birth: marital status (collected in MIHA as single, cohabitating, widowed/divorced/separated, or married, and coded here as unmarried or married after bivariate analyses revealed that women in every other category were at 
elevated risk of preterm birth when compared to married women); maternal age (from birth certificates, and coded as $15-19,20-24$, and $35+$ compared to 25-34 years); maternal parity (from birth certificates, and coded as no previous births, one to three previous births (the reference group), or four previous births); previous preterm birth (collected in MIHA, and coded as any versus none); and maternal smoking during pregnancy (collected in MIHA, and coded as any smoking versus no smoking throughout the entire pregnancy). Data were available for 21,712 women.

For the subset of women for whom information was available (beginning in 2003, when these questions were first added to the MIHA survey), we examined a number of additional covariates that might be associated with paternal or maternal education and preterm birth. These included a woman's self-report of: food insecurity, defined and coded according to USDA standards; occurrence during pregnancy of stressful life events including having bills that she could not pay, job loss, separation or divorce, physical abuse, homelessness, incarceration, economic hardship, or a lack of emotional and/or practical support; having had a usual source of pre-pregnancy care; overall health before pregnancy, rated as excellent, very good, good, fair or poor; whether or not her partner was happy about the pregnancy; whether the pregnancy was intended; and whether her partner wanted the pregnancy.

\section{Statistical Analyses}

While the number of respondents is presented here as unweighted counts, all other results have been weighted for survey design characteristics.

Although fewer than $3 \%$ of women were missing data on other variables including maternal education, data on both paternal education and family income were missing for $\sim 10 \%$ of the sample. While descriptive tables include women with missing data as a separate category, we calculated all odds ratios from models created after values for missing data were estimated using multiple imputation [18]. Generally, imputation is considered an improvement on complete case analysis or overall mean imputation [18, 19]. Imputed values were based on averages of five imputations and were conditional upon other observed variables in the final model.

Using variables selected based on a priori knowledge of likely risk factors for preterm birth, we first calculated unadjusted odds ratios to examine the association between each predictor variable and preterm birth. We then carried out a series of two-variable logistic regression models to examine the effect of each selected risk factor on the association between paternal education and preterm birth; in each of these models, preterm birth was the outcome and paternal education and a single additional variable were included as predictors. Finally, we performed multivariable logistic regression to examine how the estimated association between paternal education and preterm birth changed when controlling for multiple variables simultaneously. In this regression model, we formally tested for two separate interactions - between paternal education and race/ethnicity and between paternal and marital status — on a priori grounds that these two variables could modify the association between paternal education and preterm birth.

Data were analyzed using STATA 10.0 SE [20].

\section{Results}

Approximately ten percent of women in the weighted survey sample had preterm births. As seen in the unadjusted results presented in Table 1, a woman was significantly more likely to have a preterm birth if she or her baby's father had not completed college or if her family income was at or below $200 \%$ of the federal poverty level. African-American women and US-born Latinas were also at elevated risk of preterm birth, as were unmarried women, women between 15 and 19 years of age or 35 years and older, and women giving birth to either their first or fifth or subsequent baby (Table 1).

In two-variable models, paternal education remained significantly associated with preterm birth after controlling separately for maternal education (model 1), family income (model 2), and racial or ethnic group (model 3); across these three models, the odds of preterm birth were higher for almost every paternal education group when compared with college graduates (Table 2). While family income and race/ethnicity remained significant (models 2 and 3), the association between maternal education and preterm birth was no longer statistically significant after adjustment for paternal education only (model 1).

After adjustment for multiple covariates that could be confounders or mediators of the association between paternal education and preterm birth, women whose infants' fathers had not completed high school were $\sim 21 \%$ more likely to give birth preterm than women whose infants' fathers had completed college; family income and maternal education were no longer significantly associated with preterm birth (Table 3). The likelihood of preterm birth remained elevated for women who were not married, were 35 years of age or older, were delivering their first birth, had a previous preterm birth, or smoked during pregnancy (Table 3).

Because of concerns about possible collinearity between paternal and maternal education, we calculated the correlation between these two variables and reran all multivariable models without paternal education. Although the 
Table 1 Characteristics of women in MIHA, 1999-2005, and unadjusted odds ratios for preterm birth

\begin{tabular}{|c|c|c|c|}
\hline Variable & $N^{\mathrm{a}}$ & $\begin{array}{l}\text { Preterm } \\
\text { birth }(\%)^{\mathrm{b}}\end{array}$ & OR $(95 \% \mathrm{CI})$ \\
\hline
\end{tabular}

Paternal education

\begin{tabular}{|c|c|c|c|}
\hline Completed college & 4,259 & 7.8 & 1.00 \\
\hline Some college & 3,492 & 9.6 & $1.29(1.10,1.52)$ \\
\hline High school & 6,140 & 10.3 & $1.39(1.22,1.59)$ \\
\hline$<$ High school & 5,165 & 10.3 & $1.40(1.22,1.61)$ \\
\hline Missing & 1,990 & 12.6 & $\mathrm{c}$ \\
\hline \multicolumn{4}{|l|}{ Poverty status } \\
\hline$>400 \%$ & 4,085 & 8.4 & 1.00 \\
\hline $301-400 \%$ & 1,379 & 8.7 & $1.06(0.86,1.32)$ \\
\hline $201-300 \%$ & 1,957 & 9.4 & $1.16(0.97,1.39)$ \\
\hline $101-200 \%$ & 4,339 & 9.4 & $1.21(1.04,1.41)$ \\
\hline$\leq 100 \%$ & 7,333 & 11.2 & $1.42(1.25,1.61)$ \\
\hline Missing & 1,953 & 10.1 & $\mathrm{c}$ \\
\hline \multicolumn{4}{|l|}{ Maternal education } \\
\hline Completed college & 4,636 & 8.3 & 1.00 \\
\hline Some college & 4,054 & 9.5 & $1.19(1.03,1.38)$ \\
\hline High school & 5,832 & 10.3 & $1.29(1.13,1.48)$ \\
\hline$<$ High school & 6,097 & 10.9 & $1.35(1.19,1.54)$ \\
\hline Missing & 427 & 9.3 & $\mathrm{c}$ \\
\hline \multicolumn{4}{|l|}{ Maternal race/ethnicity } \\
\hline White & 7,757 & 9.2 & 1.00 \\
\hline African-American & 3,226 & 15.0 & $1.74(1.52,2.00)$ \\
\hline Latina_foreign-born & 6,563 & 9.2 & $1.02(0.91,1.14)$ \\
\hline Latina-US-born & 3,500 & 10.8 & $1.17(1.03,1.33)$ \\
\hline \multicolumn{4}{|l|}{ Marital status } \\
\hline Married & 12,850 & 8.7 & 1.00 \\
\hline Single/living as married & 8,196 & 11.9 & $1.43(1.31,1.57)$ \\
\hline \multicolumn{4}{|l|}{ Maternal age } \\
\hline $25-34$ (Ref) & 10,290 & 9.0 & 1.00 \\
\hline $15-19$ & 2,332 & 12.3 & $1.37(1.18,1.58)$ \\
\hline $20-24$ & 5,124 & 9.8 & $1.10(0.99,1.24)$ \\
\hline $35+$ & 3,300 & 11.2 & $1.27(1.12,1.44)$ \\
\hline \multicolumn{4}{|l|}{ Parity } \\
\hline 2-4 Births (ref) & 11,876 & 9.3 & 1.00 \\
\hline 1 Birth & 8,199 & 10.2 & $1.09(0.99,1.20)$ \\
\hline $5+$ Births & 971 & 14.4 & $1.59(1.31,1.94)$ \\
\hline \multicolumn{4}{|l|}{ Previous PTB } \\
\hline No & 19,363 & 8.6 & 1.00 \\
\hline Yes & 1,683 & 25.5 & $3.64(3.22,4.12)$ \\
\hline \multicolumn{4}{|c|}{ Mother smoked during pregnancy } \\
\hline No & 18,906 & 9.5 & 1.00 \\
\hline Yes & 2,140 & 13.2 & $1.46(1.27,1.67)$ \\
\hline
\end{tabular}

a Unweighted

b Weighted to reflect sampling frame

c No odds ratios are presented for missing categories because missing values were multiply imputed correlation between maternal and paternal education was relatively high $(\rho=0.74)$, the association between maternal education and preterm birth remained statistically nonsignificant in models without paternal education for each of the three groups investigated (all women, unmarried women, and married women).

While the association between paternal education and preterm birth did not vary significantly across racial/ethnic groups $[F(9,24,801)=0.79 ; P=0.63]$, we found marginally significant evidence of an interaction between paternal education and marital status $[F(3,24,807)=$ 2.15; $P=0.09$ ]. Results for the full model stratified by marital status (Table 3) indicate that, after adjustment for multiple covariates, the magnitude of the association between paternal education and preterm birth is greater for unmarried women than for married women. Specifically, lower paternal education is associated with greater odds of preterm birth among unmarried women relative to married women, with a strong negative paternal education gradient in preterm birth observed among unmarried women.

Among the subset of women for whom data on additional covariates were available, only two of these additional covariates-whether the woman's partner was happy about the pregnancy and whether the pregnancy was intended-were significantly associated with preterm birth. Including these two variables in the full model, however, did not change the results presented in Table 3 .

\section{Discussion}

Maternal and child health research has routinely considered maternal, but rarely paternal, education as a risk factor for many outcomes. The results presented here suggest that paternal education may represent an important additional marker of risk for preterm birth among childbearing women, particularly among unmarried women. While the magnitude of elevations in risk for preterm birth associated with lower paternal educational attainment suggested by our findings could be considered modest, the potential impact on birth outcomes and health later in life at the population level is substantial, given that nearly one in ten births is preterm and that $80 \%$ of California babies had fathers who had not completed college. Given the diversity of California's population, and the fact that slightly more than $13 \%$ of U.S. births occur in this state [21], the results of this study are likely to be informative at a national level as well.

We were unable to examine maternal and paternal wealth (because neither data source included information on accumulated assets) or occupation (because of concerns 
Table 2 Two-variable models of the associations between paternal educational level and: maternal educational level (model 1), poverty status (model 2), and maternal race/ethnicity (model 3), and the odds of preterm birth among California women in MIHA, 1999-2005 ( $n=21,046)$

\begin{tabular}{|c|c|c|c|c|c|}
\hline Model 1 & OR $(95 \% \mathrm{CI})$ & Model 2 & OR $(95 \% \mathrm{CI})$ & Model 3 & OR $(95 \% \mathrm{CI})$ \\
\hline Paternal education & & \multicolumn{2}{|l|}{ Paternal education } & \multicolumn{2}{|l|}{ Paternal education } \\
\hline Completed college & 1.00 & Completed college & 1.00 & Completed college & 1.00 \\
\hline Some college & $1.24(1.04,1.48)$ & Some college & $1.23(1.04,1.45)$ & Some college & $1.28(1.09,1.51)$ \\
\hline High school & $1.29(1.09,1.52)$ & High school & $1.25(1.07,1.46)$ & High school & $1.39(1.21,1.61)$ \\
\hline$<$ High school & $1.25(1.02,1.53)$ & $<$ High school & $1.18(0.99,1.42)$ & $<$ High school & $1.57(1.33,1.85)$ \\
\hline Maternal education & & \multicolumn{2}{|c|}{ Poverty status (\% FPL) } & \multicolumn{2}{|l|}{ Racelethnicity } \\
\hline Completed college & 1.00 & $>400 \%$ & 1.00 & White & 1.00 \\
\hline Some college & $1.07(0.91,1.26)$ & $300-400 \%$ & $1.00(0.80,1.25)$ & African-American & $1.60(1.39,1.83)$ \\
\hline High school & $1.12(0.94,1.32)$ & $200-300 \%$ & $1.07(0.88,1.29)$ & Latina-foreign-born & $0.84(0.73,0.97)$ \\
\hline \multirow[t]{2}{*}{$<$ High school } & $1.17(0.96,1.41)$ & $100-200 \%$ & $1.09(0.91,1.30)$ & Latina-US-born & $1.02(0.89,1.18)$ \\
\hline & & $<100 \%$ & $1.27(1.08,1.51)$ & & \\
\hline
\end{tabular}

about the validity of birth certificate information [22]), and also did not examine area-based measures of socioeconomic factors. In addition, the available data on education, which focused on educational attainment, did not include information on the quality of education. Paternal education may thus reflect important aspects of the mother's social and economic experiences and/or health-related behaviors that are incompletely captured by measures of maternal education, family income, or socioeconomically linked demographic variables such as age, parity, and marital status. This possibility is supported by the Whitehall studies in the United Kingdom, which found that a woman's health behaviors corresponded more closely to her husband's social class than to her own [23]. In the United States, a father's socioeconomic information may represent the couple's social position more completely than the mother's, given the persistent gender gap in occupation and income [24], even among college graduates [25]. As a marker of relative social status, paternal education may represent the father's ability to contribute time, energy, and resources to support the mother's health before, during, and after pregnancy.

Especially noteworthy was the attenuation of effects of both maternal education and family income after control for paternal education. While the relatively weak associations of maternal education and family income with preterm birth after adjustment for paternal education could reflect multicollinearity among variables included in the final model, this explanation is unlikely. The three socioeconomic variables used in this analysis are not highly correlated, as noted above and in previously published studies of this population [26]. In two-variable models with paternal education and either maternal education or family income, the effect of paternal education remained significantly associated with preterm birth while the effects of maternal education and family income were greatly attenuated. Other recognized risk factors, including older maternal age and African-American race, remained associated with preterm birth in our final multivariable model, increasing our confidence that our findings represent real phenomena. Some covariates included in the final multivariable model may mediate the association between paternal education and preterm birth, and the increased risk associated with low levels of paternal education may therefore be conservative. We can only speculate about the perhaps surprising finding that paternal education effects were more pronounced among unmarried women; one explanation could be that paternal education represents the father's contribution to family income that may otherwise not be reflected for many unmarried women.

Studies that use educational attainment as a key predictor often exclude individuals younger than 24 years of age, assuming that these individuals have not had time to complete college. When we reran the multivariable model in Table 3 limiting the sample to mothers and fathers ages 24 or older, the point estimates differed by $<5 \%$ while the confidence intervals increased considerably; we thus elected not to exclude mothers from the sample based on either maternal or paternal age. Also similar to previous studies [27], women in MIHA with missing partner information on birth certificates were at higher risk for adverse birth outcomes than women with complete partner information; the characteristics that put women with missing partner information at higher risk should be investigated further. These analyses excluded Asian-American and Native American/ American Indian women and those of "other" or unknown racial or ethnic group, potentially limiting the generalizability of our findings to women in these groups. Linkage with birth certificates provided data for key demographic and outcome variables, which have generally demonstrated 
Table 3 Multivariate odds ratios for the odds of preterm birth among all women in MIHA, 1999-2005 $(n=21,046)$, unmarried women $(n=8,196)$, and married women $(n=12,850)$

\begin{tabular}{|c|c|c|c|c|c|}
\hline \multirow[t]{2}{*}{ Variable } & \multirow{2}{*}{$\begin{array}{l}\text { All women } \\
\text { OR }(95 \% \mathrm{CI})\end{array}$} & \multicolumn{2}{|c|}{ Unmarried women } & \multicolumn{2}{|c|}{ Married women } \\
\hline & & $N$ & OR $(95 \% \mathrm{CI})$ & $N$ & OR $(95 \% \mathrm{CI})$ \\
\hline \multicolumn{6}{|l|}{ Paternal education } \\
\hline Completed college & 1.00 & 335 & 1.00 & 3,924 & 1.00 \\
\hline Some college & $1.21(1.01,1.46)$ & 945 & $1.46(0.92,2.31)$ & 2,547 & $1.22(1.00,1.48)$ \\
\hline High school & $1.21(1.01,1.44)$ & 2,772 & $1.83(1.20,2.78)$ & 3,368 & $1.03(0.83,1.28)$ \\
\hline$<$ High school & $1.26(1.01,1.58)$ & 2,468 & $1.95(1.23,3.10)$ & 2,697 & $1.05(0.80,1.37)$ \\
\hline Missing education & $\mathrm{a}$ & 1,676 & $\mathrm{a}$ & 314 & $\mathrm{a}$ \\
\hline \multicolumn{6}{|l|}{ Poverty status } \\
\hline$>400 \%$ & 1.00 & 268 & 1.00 & 3,817 & 1.00 \\
\hline $301-400 \%$ & $1.03(0.82,1.29)$ & 186 & $0.85(0.45,1.59)$ & 1,193 & $1.08(0.85,1.38)$ \\
\hline $201-300 \%$ & $1.06(0.87,1.30)$ & 424 & $0.91(0.53,1.54)$ & 1,533 & $1.14(0.91,1.42)$ \\
\hline $101-200 \%$ & $1.04(0.85,1.27)$ & 1,746 & $0.89(0.56,1.42)$ & 2,593 & $1.13(0.90,1.43)$ \\
\hline$\leq 100 \%$ & $1.12(0.91,1.38)$ & 4,692 & $0.95(0.60,1.52)$ & 2,641 & $1.20(0.91,1.58)$ \\
\hline Missing & $\mathrm{a}$ & 880 & a & 1,073 & a \\
\hline \multicolumn{6}{|l|}{ Maternal education } \\
\hline Completed college & 1.00 & 449 & 1.00 & 4,187 & 1.00 \\
\hline Some college & $1.01(0.84,1.20)$ & 1,350 & $0.92(0.62,1.36)$ & 2,704 & $1.04(0.85,1.27)$ \\
\hline High school & $1.03(0.85,1.24)$ & 2,826 & $0.83(0.57,1.22)$ & 3,006 & $1.18(0.95,1.47)$ \\
\hline$<$ High school & $1.09(0.88,1.35)$ & 3,377 & $0.90(0.59,1.36)$ & 2,720 & $1.20(0.91,1.59)$ \\
\hline Missing & a & 194 & a & 233 & a \\
\hline \multicolumn{6}{|l|}{ Maternal race/ethnicity } \\
\hline White & 1.00 & 1,641 & 1.00 & 6,116 & 1.00 \\
\hline African-American & $1.43(1.23,1.66)$ & 2,049 & $1.47(1.17,1.83)$ & 1,177 & $1.39(1.12,1.73)$ \\
\hline Latina-foreign-born & $0.88(0.76,1.03)$ & 2,699 & $0.88(0.70,1.12)$ & 3,864 & $0.90(0.73,1.11)$ \\
\hline Latina-US-born & $1.02(0.88,1.18)$ & 1,807 & $1.03(0.82,1.29)$ & 1,693 & $1.01(0.82,1.24)$ \\
\hline \multicolumn{6}{|l|}{ Marital status } \\
\hline Married/living as married & 1.00 & N/A & & N/A & \\
\hline Single & $1.23(1.10,1.38)$ & N/A & & N/A & \\
\hline \multicolumn{6}{|l|}{ Maternal age } \\
\hline $25-34$ & 1.00 & 2,757 & 1.00 & 7,533 & 1.00 \\
\hline $15-19$ & $1.00(0.83,1.19)$ & 1,928 & $1.08(0.85,1.36)$ & 404 & $1.08(0.77,1.52)$ \\
\hline $20-24$ & $0.93(0.82,1.05)$ & 2,824 & $1.02(0.85,1.23)$ & 2,300 & $0.86(0.72,1.04)$ \\
\hline $35+$ & $1.29(1.13,1.48)$ & 687 & $1.41(1.08,1.83)$ & 2,613 & $1.28(1.09,1.50)$ \\
\hline \multicolumn{6}{|l|}{ Parity } \\
\hline 2-4 Births & 1.00 & 3,890 & 1.00 & 7,986 & 1.00 \\
\hline 1 Birth & $1.31(1.17,1.46)$ & 3,882 & $1.17(0.98,1.40)$ & 4,317 & $1.43(1.24,1.65)$ \\
\hline $5+$ Births & $1.12(0.90,1.40)$ & 424 & $1.03(0.75,1.42)$ & 547 & $1.17(0.86,1.59)$ \\
\hline \multicolumn{6}{|l|}{ Previous PTB } \\
\hline No & 1.00 & 7,522 & 1.00 & 11,841 & 1.00 \\
\hline Yes & $3.76(3.30,4.29)$ & 674 & $4.47(3.65,5.46)$ & 1,009 & $3.31(2.77,3.96)$ \\
\hline \multicolumn{6}{|c|}{ Mother smoked during pregnancy } \\
\hline No & 1.00 & 6,775 & 1.00 & 12,131 & 1.00 \\
\hline Yes & $1.21(1.05,1.41)$ & 1,421 & $1.38(1.14,1.66)$ & 719 & $0.96(0.72,1.27)$ \\
\hline
\end{tabular}

${ }^{a}$ No odds ratios are presented for missing categories because missing values were imputed using multiple imputation by chained equations

good validity and reliability [28-30]. While the accuracy of gestational age information in birth certificate data has been shown to be particularly problematic for preterm births before 32 weeks [31], the fact that MIHA replaces improbable gestational ages with imputed values based on birth weight and sex reduces the likelihood of bias due to 
misclassification of preterm birth according to paternal or maternal education or other key variables in this study.

Despite its limitations, our study is unique because of the breadth of socioeconomic and demographic measures included in the analyses; earlier studies have typically lacked information on at least one of the key socioeconomic variables-paternal education, maternal education, or family income-included here. While previous studies have also been limited by their handling of missing data, the present analysis uses multiple imputation, a technique that reduces the biases introduced by other simpler methods for handling missing data, such as complete case analysis, overall mean imputation, and the indicator method $[19,32$, 33]. Multiple imputation cannot fully eliminate the potential for bias related to the distribution of missing values, but it is an improvement upon techniques that either exclude missing values completely or replace missing values with overall averages or indicator values.

Previous research on socioeconomic disparities in birth outcomes has focused almost exclusively on maternal characteristics. Recent methodological work, however, suggests the importance of generally measuring a wider range of social factors in health research [12]. The role of fathers has recently received increased attention in social science and biomedical research [34] and in public health strategies to reduce racial/ethnic and socioeconomic disparities in maternal and child health outcomes [35, 36], and it is biologically plausible that paternal factors could affect birth outcomes through a range of pathways involving material and psychosocial resources as well as stress. While the findings presented here do not establish a causal role for paternal factors in adverse birth outcomes, they do indicate the need to widen the scope of social factors considered in future research to include information on a range of paternal as well as maternal socioeconomic factors. Clarifying the role of these factors may lead to better understanding of the underlying causes of disparities in birth outcomes and provide new direction for interventions to eliminate those disparities, a major U.S. public health initiative for the past decade [37].

Acknowledgments The data source used for this study represents a collaborative effort of the Maternal, Child and Adolescent Program, California Department of Public Health, and of the University of California, San Francisco.

Open Access This article is distributed under the terms of the Creative Commons Attribution Noncommercial License which permits any noncommercial use, distribution, and reproduction in any medium, provided the original author(s) and source are credited.

\section{References}

1. Slattery, M. M., \& Morrison, J. J. (2002). Preterm delivery. The Lancet, 360(9344), 1489-1497.
2. Institute of Medicine: Committee on Understanding Premature Birth, Assuring Healthy Outcomes. (2007). Preterm birth: Causes, consequences, and prevention. Washington, DC: The National Academies Press.

3. Kramer, M. S., Séguin, L., Lydon, J., \& Goulet, L. (2000). Socioeconomic disparities in pregnancy outcome: Why do the poor fare so poorly? Paediatric and Perinatal Epidemiology, 14, 194210.

4. Lu, M. C., \& Halfon, N. (2003). Racial and ethnic disparities in birth outcomes: A life-course perspective. Maternal and Child Health Journal, 7(1), 13-30.

5. Parker, J. D., Schoendorf, K. C., \& Kiely, J. L. (1994). Associations between measures of socioeconomic status and low birth weight, small for gestational age, and premature delivery in the United States. Annals of Epidemiology, 4(4), 271-278.

6. Nicolaidis, C., Ko, C. W., Saha, S., \& Koepsell, T. D. (2004). Racial discrepancies in the association between paternal vs. maternal educational level and risk of low birthweight in Washington State. BMC Pregnancy Childbirth, 4(1), 10.

7. Parker, J. D., \& Schoendorf, K. C. (1992). Influence of paternal characteristics on the risk of low birth weight. American Journal of Epidemiology, 136(4), 399-407.

8. Berg, C. J., Wilcox, L. S., \& d'Almada, P. J. (2001). The prevalence of socioeconomic and behavioral characteristics and their impact on very low birth weight in black and white infants in Georgia. Maternal and Child Health Journal, 5(2), 75-84.

9. Subramanian, S. V., Chen, J. T., Rehkopf, D. H., Waterman, P. D., \& Krieger, N. (2006). Comparing individual- and area-based socioeconomic measures for the surveillance of health disparities: A multilevel analysis of Massachusetts births, 1989-1991. American Journal of Epidemiology, 164(9), 823-834.

10. Gould, J. B., Madan, A., Qin, C., \& Chavez, G. (2003). Perinatal outcomes in two dissimilar immigrant populations in the United States: A dual epidemiologic paradox. Pediatrics, 111(6 Pt 1), e676-e682.

11. Cubbin, C., Braveman, P. A., Marchi, K. S., Chavez, G. F., Santelli, J. S., \& Gilbert, B. J. (2002). Socioeconomic and racial/ ethnic disparities in unintended pregnancy among postpartum women in California. Maternal and Child Health Journal, 6(4), 237-246.

12. Braveman, P. A., Cubbin, C., Egerter, S., Chideya, S., Marchi, K. S., Metzler, M., et al. (2005). Socioeconomic status in health research: One size does not fit all. Jama, 294(22), 2879-2888.

13. Chung, E. K., Hung, Y. Y., Marchi, K., Chavez, G. F., \& Braveman, P. (2003). Infant sleep position: Associated maternal and infant factors. Ambulatory Pediatrics, 3(5), 234-239.

14. Heck, K. E., Schoendorf, K. C., Chavez, G. F., \& Braveman, P. (2003). Does postpartum length of stay affect breastfeeding duration? A population-based study. Birth, 30(3), 153-159.

15. Galbraith, A. A., Egerter, S. A., Marchi, K. S., Chavez, G., \& Braveman, P. A. (2003). Newborn early discharge revisited: Are California newborns receiving recommended postnatal services? Pediatrics, 111(2), 364-371.

16. Mattison, D. R., Damus, K., Fiore, E., Petrini, J., \& Alter, C. (2001). Preterm delivery: A public health perspective. Paediatric and Perinatal Epidemiology, 15(Suppl 2), 7-16.

17. Department of Health, Human Services. (2005). Annual update on the HHS poverty guidelines. Federal Register, 70(33), 8373-8375.

18. Schafer, J. L., \& Graham, J. W. (2002). Missing data: Our view of the state of the art. Psychol Methods, 7(2), 147-177.

19. Donders, A. R., van der Heijden, G. J., Stijnen, T., \& Moons, K. G. (2006). Review: A gentle introduction to imputation of missing values. Journal of Clinical Epidemiology, 59(10), 10871091.

20. StataCorp. (2007). Stata statistical software: Release 10. College Station, TX: StataCorp LP. 
21. Martin, J. A., Hamilton, B. E., Sutton, P. D., Ventura, S. J., Menacker, F., Kirmeyer, S., et al. (2009). Births: Final data for 2006. National Vital Statistics Representatives, 57(7), 1-102.

22. Brender, J. D., Suarez, L., \& Langlois, P. H. (2008). Validity of parental work information on the birth certificate. BMC Public Health, 8, 95.

23. Bartley, M., Martikainen, P., Shipley, M., \& Marmot, M. (2004). Gender differences in the relationship of partner's social class to behavioural risk factors and social support in the Whitehall II study. Social Science and Medicine, 59(9), 1925-1936.

24. Holzer, H., \& Neumark, D. (2000). Assessing affirmative action. Journal of Economic Literature, 38(3), 483-568.

25. Zhang, L. (2008). Gender and racial gaps in earnings among recent college graduates. Review of Higher Education, 32(1), 51.

26. Braveman, P., Cubbin, C., Marchi, K. S., Egerter, S., \& Chavez, G. (2001). Measuring socioceconomic status in studies of racial/ ethnic disparities: Examples from maternal and child health. Public Health Reports, 116(5), 449-463.

27. Tan, H., Wen, S. W., Walker, M., \& Demissie, K. (2004). Missing paternal demographics: A novel indicator for identifying high risk population of adverse pregnancy outcomes. BMC Pregnancy Childbirth, 4(1), 21.

28. Zollinger, T. W., Przybylski, M. J., \& Gamache, R. E. (2006). Reliability of Indiana birth certificate data compared to medical records. Annals of Epidemiology, 16(1), 1-10.

29. DiGiuseppe, D. L., Aron, D. C., Ranbom, L., Harper, D. L., \& Rosenthal, G. E. (2002). Reliability of birth certificate data: A multi-hospital comparison to medical records information. Maternal and Child Health Journal, 6(3), 169-179.

30. Reichman, N. E., \& Hade, E. M. (2001). Validation of birth certificate data. A study of women in New Jersey's HealthStart program. Annals of Epidemiology, 11(3), 186-193.
31. Schoendorf, K. C., \& Branum, A. M. (2006). The use of United States vital statistics in perinatal and obstetric research. American Journal of Obstetrics and Gynecology, 194(4), 911-915.

32. Greenland, S., \& Finkle, W. D. (1995). A critical look at methods for handling missing covariates in epidemiologic regression analyses. American Journal of Epidemiology, 142(12), 12551264.

33. van der Heijden, G. J., Donders, A. R., Stijnen, T., \& Moons, K. G. (2006). Imputation of missing values is superior to complete case analysis and the missing-indicator method in multivariable diagnostic research: A clinical example. Journal of Clinical Epidemiology, 59(10), 1102-1109.

34. Tamis-LeMonda, C. S., \& Cabrera, N. (2002). Handbook of father involvement: Multidisciplinary perspectives. Mahwah, NJ: Lawrence Erlbaum Assocaites.

35. California Department of Public Health. (2007). Black infant health program [cited 2009 March 14th]; Available from: http:// www.cdph.ca.gov/programs/bih/Pages/default.aspx.

36. Georgia Department of Human Resources. (2005). Fathers' involvement in maternal and child health increases positive birth outcomes [cited 2009 March 14th]; Available from: http://www. dhr.georgia.gov/portal/site/DHR/menuitem.3d43c0fad7b3111b50c 8798dd03036a 0/vgnextoid=1 a6fc5f63e684010VgnVCM100000 bf01010aRCRD\&vgnextchannel=b49807b35414ff00VgnVCM 100000bf01010aRCRD.

37. U.S. Department of Health, Human Services. (2000). Healthy people 2010 (2nd ed.). Washington, DC: U.S. Government Printing Office. 